\title{
Which Competence? A Comparative Analysis of Culture-specific vs. Culture-generic Intercultural Competence Development
}

\author{
Stefanie A. Stadler \\ Department of Linguistics and Multilingual Studies, School of Humanities, Nanyang Technological University, Singapore
}

Copyright $\subset 2017$ by authors, all rights reserved. Authors agree that this article remains permanently open access under the terms of the Creative Commons Attribution License 4.0 International License

\begin{abstract}
This paper takes a critical look at the type of approaches that prevail in the field of intercultural competence development and the uncritical perspectives with which these views are often circulated in academia and the wider community of international business and intercultural sojourns. It is all-too-common to find papers, models and frameworks that equate intercultural competence with culture specific competence. However, such approaches can never accurately portray a culture or prepare a person to deal with people in an appropriate, flexible and adaptable manner. This paper aims to assess and weigh the benefits and disadvantages of both culture-specific and culture-generic intercultural competence development, arguing that a combined approach constitutes the most desirable compromise between feasibility of training and effectiveness of training outcomes.
\end{abstract}

Keywords Intercultural Communication, Intercultural Competence, Culture-specific Competence, Culture-generic Competence

\section{Introduction}

There is little doubt that intercultural competence development has become an increasingly valuable and sought-after asset in an increasingly interconnected world and globalized marketplace (see [1] \& [2]). Ineffectiveness in international business is clearly linked to undesirable outcomes, as "there is no doubt that the cost of failure [...] is high" [3] (p. 526). Besides strong motivations to create better platforms for successful intercultural transactions, intercultural competence development initiatives have also been clearly linked to improving intercultural success, hence there is not only strong motivation, but also strong evidence for effectiveness of such development provisions. Beach et al. [4] speak of excellent evidence that cultural competence training impacts intermediate outcomes such as [...] knowledge, attitudes and skills. Johnson et al.'s [3] study confirms this, presenting clear evidence of a positive correlation between intercultural training and intercultural effectiveness. In other words, intercultural competence development has proven an invaluable tool for an increasingly important skill-set. While I have yet to come across a single academic argument against the necessity of intercultural competence development, there seems to be little unity regarding what the ideal intercultural competence set should comprise. According to Fantini [2] and Deardorff [5], there is no agreement among interculturalists what is to be understood when talking about intercultural competence. In a similar vein Johnson et al. [3] criticize the lack of an adequate conceptualization of intercultural competence. Many researchers have pointed to particular competencies that together should amount to intercultural competence, such as mindfulness, flexibility and openness [6], [7], [8], [9], [10], [11], [12], but there is little discussion of the type of competences there are, which one people should strive for and how to best develop such competence.

One of the main controversies in this discussion, as I see it, and one of the most fundamental issues with competence assessment, lies in the differentiation of culture-specific as opposed to culture-generic competence (see [13]). The dichotomy, actually, exists less about which of these types of competence is the more desirable (culture-generic) and more about which of the two is more feasible, both in terms of acquisition and assessment (culture-specific). While it has been established that there is a need to move towards culture-generic competence development, there seems to exist a deep void between insight and application - or as Johnson et al. [3] (p. 525) put it, between "'knowing' and 'doing"'. Hunter et al. [14] emphasize the need for what they refer to as global-ready graduate/citizen. Stier [15] and Stadler [1], therefore, both push for the advance of the inclusion of culture-generic competence development in modern language education curricula and Higher Education 
Institutions respectively. Although the need for this shift in competence development has been established, Hunter et al. [14] lament the fact that little tangible research exists to date that outlines concrete skills, knowledge, attitudes and experiences that are required to become interculturally competent.

In this paper, I will discuss the values and flaws of both culture-specific and culture-generic approaches to intercultural competence building. I propose a holistic standpoint which consolidates the views that both types of competence can make a valuable contribution. Instead of seeing them as mutually exclusive attempts to achieve the same goal, I postulate an integrated approach that sees them as complementary developmental stages.

\section{Culture-specific Competence}

One of the main reasons why culture-specific competence is seen as desirable and has been pursued with far greater drive than culture-generic competence is the notion of a presumed 'quick-fix'. With its fundamentally practical orientation, the business literature and business world started off dispersing insights into business etiquette and practices, especially with regard to economically viable cultures, such as China. In other words, their orientation has been, to a large extent, on culture-specific insights in order to quickly boost business efficiency in a particular cultural context (see [16]).

The idea that a business person can prepare him/herself within a short space of time of course holds appeal in a sector that has at its central core element the drive to make money, and - at least in the West - people work under the assumption that 'time is money'. Or as Beach et al. [4] put it: "organizations $[\ldots]$ have limited resources to conduct educational programs to improve cultural competence" ( $p$. 366). As a consequence, the attitude towards intercultural competence development has been that it should be as time and cost-effective as possible. Storti [17] addresses this very issue by stating that business people expect to be trained in so-called "do's and don'ts" (p. 273), but that such an approach to training is overrated and nowhere near as valuable as other training contents.

A second major factor in why culture-specific knowledge is seen as desirable, is the undeniable benefit that culture-specific information tends to be very concrete, very tangible and - relatively speaking - easy to implement. In any form of competence development, there is nothing quite as disheartening as vague terminology and seemingly 'wishy-washy' concepts without any clear guidance on how to implement such new-found skills or indeed what exactly the benefits are. This is particularly true in the light that most people have a tendency for at least a small degree of uncertainty avoidance when faced with new countries and cultures. Duronto et al. [18], for example, discovered that anxiety and uncertainty are associated with avoidance in communication with strangers. Culture-specific competence development does not only provide clear behavioural guidelines, but because guidelines are mostly on behavioural aspects it has the extra benefit of being implementable with immediate effect and creates expectations, thereby reducing uncertainty to a substantial degree. Ewington and Trickey [19] suggest that business people might also be somewhat apprehensive of intercultural competence development and thus approach it with an attitude that they are not interculturalists. This would naturally make them gravitate towards easier and faster solutions to the problem of cultural differences.

However, despite its superficial appeal, culture-specific competence is fraught, because of its limited applicability. For one, culture-specific competence, by its very nature, is highly prescriptive. For example, many China-specific publications and business training manuals mention gift-giving or business card etiquette (see [2], [21], [22], [23], [24], [25]). Not that this information is not true, but rather than fully grasping the underlying cultural values and principles, the focus is on behavioural expectations. Except, these days, it is not at all clear what to expect in intercultural encounters. A Chinese business man, who has spent his adolescent years living, studying and working in a US context, may well be handing you his business card with one hand in an attempt to accommodate you, which then raises the question what is an appropriate response when cultural practices get mixed? Clear instructions of how to behave can be more hindering than helpful and, as such, prescribed behaviours often get in the way of vital competencies such as flexibility. Johnson et al. [3] speak of a lack of fostering a participant's own cultural introspection. Culture-specific instructions on how to behave and act are therefore only mildly helpful.

The main problem with culture-specific competence though, is that it prepares us for stereotypically expected behaviours rather than reality. Bennett [26] refers to minimization as a developmental stage, which essentially relates to stereotypes, seeing as emphasis is placed on shared commonalities, in other words a simplification and overgeneralization of expected behaviours. The reality is that in countries, such as China, there is a very diverse range of behavioural patterns and expectations, depending on various factors, such as age, educational background, status, exposure, experience, attitudes etc. There is no one 'Chinese'. Although Bennett [26] refers to this stage as a benign form of ethnocentrism, Hammer [27] cautions that in cases where "commonality strategies [are] functionally sufficient" (p.123), it more or less fosters learners to get stuck in a minimization mindset, thereby hindering people's further intercultural development. In other words, culture-specific information does not equip us to deal with idiosyncratic variation that is present in individuals from all cultures and hampers real personal and professional growth, as it mistakenly provides a semblance of cultural functionality. Beach et al. [4] emphasize that concerns have been raised regarding whether specific cultural information, which relies 
on a knowledge-based, categorical approach promotes merely stereotypes. What is more, it is only of limited value to learn what to typically expect in terms of behaviours in a particular country, when in reality you may never encounter such behaviours. To some extent, there is a 'foreigner allowance' [1], where people are often quite willing to overlook minor faux-pas [17], however, what is considered much less forgiveable than minor behavioural transgressions is to treat other people according to stereotypical expectations. In short, people prefer to be treated like people, rather than like cultural automata and culture-specific knowledge hinders rather than fosters this.

Culture-specific knowledge also does not allow for 'updates'. This has, in fact, been one of the strongest criticisms voiced against Hofstede's culture dimensions [28]. By the time his data was published it was already largely outdated [29]. When we are presented with culture-specific information, in reality, we are presented with the snapshot of a culture at one particular point in time. However, cultures and societies develop and change. Arasaratnam and Doerfel [30] speak of the "dynamic and heterogenous nature of intercultural communication" (p.161). Singapore, for example, has essentially grown from a small colonial port to an independent economical powerhouse in the space of a couple of generations and cultural values, linguistic repertoires, behavioural patterns and international outlooks are all shifting alongside this economical growth [31]. Such changes are hard to accurately capture in culture-specific information. Although this is hardly feasible, cultural information would have to be updated permanently, if it were to be maximally useful to its users.

Culture-specific knowledge is further limited in that it is restricted to one specific culture. Learning what it means to be polite and respectful in one culture and what is expected etiquette, will require relearning all these acquired behaviours when venturing into another culture. Not only is the notion of relearning all new behavioural patterns from scratch daunting, it essentially means starting back over from the very beginning. This is not to say that none of the information learned holds across cultures, but the potential for global applicability is minimal. While this problem might not exist if sojourners or business people are trained to live, work and function in only one particular culture, the profession of healthcare provision makes it very clear that culture specific information offers little value in dealing with a diverse range of patients from multiple national backgrounds. Altshuler et al. [32] state that during intercultural training for healthcare professionals it is "impossible to orient trainees to all types of patients they are likely to encounter" (p.388). Consequently they conclude that training must avoid stereotypical notions of cultures and, in order to be effective, the mere transmission of culture specific knowledge must be avoided. Not only that, but essentially, culture specific information is often based on either organizational culture or national culture, neither of which are good platforms for studying culture [29].
A further downside is that knowledge imparted about culture-specific behaviours rarely includes an account of context-dependent levels of appropriateness. In a study on the development of pragmatic knowledge in German language learners, it became clear that students had been informed that German culture has an orientation towards very direct communication. While this is true in many contexts, the New Zealand learners applied this to hierarchical relationships, where the level of directness they demonstrated to superiors would not have been welcome in a German workplace [33]. Culture-specific information is often presented in a context-free vacuum. However, taking contextual factors into consideration, such as social and situational circumstances, addressees, power relations etc. is vital in achieving successful interaction outcomes. Spitzberg [34] and Alptekin [35] both mention the importance of contextually situated appropriateness of behaviours in intercultural competence development.

Though appealing in its approach for a variety of reasons outlined earlier, the scope of culture-specific competence is quite narrow. Despite their popularity in the business circle for ease of access, level of concrete measurable categories and easily comprehensible do's and don'ts, culture specific frameworks have not been well-received by the academic community. One of the most commonly referenced frameworks is Hofstede's culture dimensions [28], which essentially ranks countries according to a number of variables consisting of cultural values. While very systematic, and compelling in its ease of access, it is one of the most heavily criticized frameworks, that has received a vast amount of attention in the academic literature (though mostly of a negative nature). Smith [36] says of the framework that Hofstede "ignores everything [...] but the culture level comparisons" (p.123), thereby insinuating that a deeper, individual level comparison gets lost and that his work is too reductionist to be meaningful. Kirkman et al. [37], conclude that Hofstede-inspired research is "fragmented, redundant, and overly reliant on certain levels of analysis and direction of effects" (p.313). Baskerville-Morley [29] repeatedly mentions how dated Hofstede's culture dimensions [28] are, how narrow the use of categories that form the basis for analysis is, how organizational data is an unsuitable platform for cultural studies and how surveys are an unreliable method for assessing cultural differences, while McSweeney [38] refers to Hofstede's model [28] as a failure of analysis. Obviously then, the problems with such approaches far outweigh their benefits, rendering them all but meaningless at worst and providing some questionable, dated, rigid, approximate behavioural guidelines at best. As Stier [15] points out, such competence "does not ensure full culture functionality". Instead he argues in favour of what he terms processual competence, which "considers the dynamic character of intercultural competence and its interactional context" (p. 6). 


\section{Culture-generic Competence}

The most significant argument in favour of culture-generic intercultural competence development is - without a doubt that it is the only form of intercultural competence that is comprehensive and holistic in nature. It aims to provide its learner with multilayer, multilevel sets of knowledge, skills, attitudes and behaviours. It does not focus on the basis of behavioural outputs, but on truly understanding cultural differences with the aim to foster informed, comprehensive decision-making instead of parroting observable culture-specific behaviours. Crozet and Liddicoat [39] have made it clear that copying foreign cultural codes is not what intercultural competence development is about and Francis [40] has highlighted that this form of 'competence' is clearly disliked by people of the target culture group. Her research clearly indicates that a moderate form of adaptation, that demonstrates insight and respect, is much preferred over copying of behavioural norms. In this sense then, culture-generic intercultural competence is not only the better form of competence to strive for on a conceptual level, but is also the better-received type of competence. Essentially, this is all that counts in the spirit of intercultural effectiveness, because only if it is well received can it be effective.

A further benefit of culture-generic competence is that competencies acquired are transferrable. Johnson et al. [3] postulate that, what they refer to as culture-general knowledge, applies to any cultural environment. Becoming, for example, more flexible and observant in one cultural context will also serve a person equally well in another context. If anything, the level of perceptiveness is likely to sharpen and improve with exposure to multiple contexts. Because, culture-generic intercultural competence is transferrable, one of the most significant benefits of culture-generic competence is that it builds on pre-existing knowledge, experience and expertise. With exposure to each new culture, people build on and expand their repertoire. Unlike culture-specific knowledge, which requires starting over from scratch when shifting focus to a different culture, culture-generic competence is accumulative and prior experience fosters its growth.

While there is no denying that culture-generic competence is more widely applicable, consists of a more in-depth understanding and world-view and better equips people for intercultural encounters of any kind, it does not come without limitations either. Culture-generic competence tends to consist of a set of rather vague competencies. They are notoriously obscure and fuzzy, such as 'flexibility' or 'open-mindedness', which seem rather self-evident at first glance, but are difficult to implement. Their integral quality of ambiguity makes culture-generic competencies rather unappealing for most people, in part because some people find that intercultural work is already out of their comfort zone and the fact that such competencies are not clearly defined makes the task seem even more daunting. According to Duronto et al. [18] "communication between strangers is characterized by a limited amount of information about each other, by ignorance of the means to reach a goal, and by ignorance of the probable outcomes. To deal with the ambiguity that characterizes these new situations, we need information [in order to manage uncertainty]" (p.550). However, culture-generic competence only marginally fulfills this need due to its inherent fuzziness. This is not just a problem for the individual, but also for the education sector, because education relies heavily on assessment of learning and the less tangible a competency is, the harder it makes it to assess [30], which is why the education sector also favours culture-specific (and therefore assessable) competence. The fact that all of intercultural work is wholly unpredictable per se puts many people off, so when they try to overcome the difficulties of cultural diversity they gravitate towards more 'tangible' competencies that seem easier to master and promise more instant success and achievement. While this is true to some extent, it is deceiving in the long run.

What is more, culture-generic competence relies on a more autonomous approach to learning, requiring strong deduction and observation skills as well as an intrinsic motivation for self-development and ongoing improvement. However, being busy with a vast variety of commitments, such as work, family etc. that most people juggle in their lives, finding the drive to invest continuous effort for intercultural development is often a challenge. Unless someone has a very good reason to want to tackle this rather enormous task (such as a promotion or a genuine personal interest in cultures and diversity), self-improvement approaches, that rely heavily on an individual's personal engagement, rarely succeed. According to Reid and Stadler [41], "it is doubtful that unguided encouragement for self-reflection will be a very fruitful means of producing a more international perspective and outlook" (p.7).

Culture-generic competence development is also much more challenging than acquiring culture-specific skills or knowledge. This is in part because culture-generic competence is far more comprehensive and partly due to the fact that it emphasizes not only the acquisition of some behavioural concepts but the development of cognitive, attitudinal and behavioural aspects of intercultural learning. Just how difficult and complex an endeavor intercultural competence acquisition is had been amply documented in the literature. Jacobson et al. [42] speak of the complex nature of intercultural competence, Yamazaki and Kayes's [43] diagram visualizes the complexities of cross-cultural learning, while Fantini [2] discusses the multiple layers of competence development, including awareness, attitude, skills, knowledge, and language proficiency. Needless to say, it is easy to temporarily modify one's behavioural actions (such as handing over a business card with two hands), but much more challenging to grasp what the meaning behind this action is and which cultural values and traditions underlie such behavioural schemata (on a cognitive level). The most difficult though is, without a doubt, to foster a 
change in attitudes. Behaving in a certain manner and understanding why one should behave in this manner is one thing, but to actually learn to appreciate, value and accredit differences as equally valid to one's own learnt patterns is far more demanding. It is a time-consuming, holistic effort. On top of these complexities, Spitzberg [44] further highlights the complex interrelationships between individual competencies, such as the links between empathy, expressiveness and interaction management. In other words, intercultural competence does not merely demand managing and mastering one's own cognitive, affective and behavioural states, but also the ability to predict with relative accuracy how one's actions are perceived and how they are received by others, how competencies are interlinked and what effect they have on strangers across multiple cultural contexts.

As a result, probably the biggest problem with culture-generic competence development is that it requires long-term commitment and, if taken seriously, constitutes a life-long learning project. There rings a truth to idiomatic expressions such as the German "Kein Meister fällt vom Himmel" (No master falls from the heavens), meaning that no one achieves a high degree of mastery over any skill out of the blue, i.e. it requires commitment, dedication and time to achieve mastery over anything. Molinsky et al. [45] speak of a strong and conclusive correlation between implicit learning and exposure. Theories of success, such as Malcom Gladwell's [46] notion of the 10,000 hours of practice rule, in which he postulates that it takes a person 10,000 hours of practice to become really good at something essentially emphasize this same point. He claims that no successful person has achieved success without this commitment of time and effort, quoting Bill Gates as example. In a similar vein, Richard St. John [47] reinforces this viewpoint in his TEDX talk on the secrets of success. He lists practice, persistence and hard work as vital building blocks for success, quoting Rupert Murdoch, who puts his success down to hard work: "It's all hard work. Nothing comes easily". Instead, Richard St. John [48] views success as a continuous journey. Spencer-Oatey and Franklin [11] confirm this view for the realm of intercultural competence development, postulating not only the comprehensive nature which goes beyond mere knowledge acquisition as well as the length of time-frame required to acquire competence. Clearly then, to achieve a high degree of the kind of competence that really adds value and to achieve mastery over intercultural competence, the same level of practice and persistence is required. Consequently, culture-generic competence development is more deterring than it is attractive to the vast majority of people.

\section{Arguing for an Integrated, Combined Approach}

If culture-generic competence is more superior, then why am I arguing in favour of an integrated competence development model that proposes to incorporate both types of competence? In a nutshell, I believe that culture-generic intercultural competence is the more desirable kind of competence to develop and without it, even culture-specific competence will be misguided and misused. However, culture-specific knowledge does have the un-deniable bonus of being quick to study and implement and being readily available as information, so it forms a good starting point into a new culture. After all, some information is better than none. Once we have culture-specific competence as a baseline, we can then develop culture-generic skills on the basis of this information. In turn, once we have developed a set of competencies such as openness, flexibility and mindfulness then we will be able to draw on culture-specific knowledge more wisely, benefiting from its insights, rather than relying on its prescriptive guidelines. As such, I believe that the two types of competence can work hand in hand as a step by step approach to becoming a competent 'global citizen'.

While culture-specific knowledge can be a hindrance, it can also be beneficial, so long as it is implemented and employed in intelligent and meaningful ways and most importantly in a non-conformist manner. A study on healthcare provision demonstrates both points very nicely. The study found that teaching culture-specific information led to positive outcomes overall, but also made recipients more prone to stereotype and see people from that specific culture to be more similar than they are [49]. It can be helpful to know what one might encounter as it takes away some of the anxiety, provides a starting point for the encounter and equips people with some sense of behavioural expectations. Indeed, studies have shown a positive correlation between remedial action and anxiety management [50], behavioral adjustment, cognitive and attitudinal adjustment [51]. However, it needs to be implemented in the spirit of ad-hoc modification if required by the situation and circumstances, rather than rigorous adherence to stereotyped expectations. In fact, flexibility has been cited as a key criterion to intercultural adjustment and success [52].

The descriptive nature of culture-generic competencies means that a person does not approach a situation with a specific behavioural approach, rather, a person is more prepared for a situation, but does not impose a certain behaviour on a situation if the social and situational context do not suit it. Culture generic competence aims to enable people to make better choices and more appropriate judgment calls by better equipping a person to identify situationally appropriate actions. As such, it describes culturally typical behaviours without imposing it on people's actions. This approach of enabling a person to make better use of the information they hold of a culture fosters flexible behaviours, rather than a rigid outlook on cultural difference. The trick in intercultural situations is not to go into them equipped with an amassed amount of knowledge, but rather to adjust to a situation at hand even if we have no knowledge 
or understanding over a certain situation or behaviour. Nonaka and Takeuchi [53] speak of a culture-general approach which prepares for "learning how to learn" (p.430). It is based more on a deductive model than an indoctrinated model of memorization, as remaining flexible at all times and being able to learn from the situation at hand are among the most indispensable qualities in intercultural situations.

\section{Conclusions}

Arasaratnam and Doerfel [30] emphasize that a "culture-general instrument of ICC will be invaluable to intercultural trainers and practitioners" (p.161). The idea behind culture-generic intercultural competence is not that we are safe from committing faux pas ever again. Intercultural communication (or intracultural communication for that matter as well) will never be entirely safe from mistakes, errors and misunderstandings. It is in its very nature that intercultural communication is fraught with difficulty and pitfalls. The idea is that with increased culture-generic competence we substantially reduce the frequency and gravity of such incidents in a way that culture-specific competence alone would not allow for. The complexity of culture-generic competence development and the nature of the lengthy development process have meant in the past that culture-generic competence building has been regarded as a great vision that lacks potential for practical application.

However, an integrated approach that combines the benefits of both culture-specific and culture-generic competence development can accentuate the gains and strengths from both approaches while limiting or eliminating the weaknesses of each of them. The idea is to draw on the quickly accessible information and knowledge provided by the former and implement it successfully by drawing on the sensibility and sensitivity of application that can be gained from the latter approach. This form of integration then allows to achieve short and long term goals in intercultural competence development. As a consequence, because it is oriented to immediate outcomes and not only long-term goals, it will drastically increase learner satisfaction. Hence, the aim should not be to ignore culture-specific competence entirely, but to emphasize the development of skills to implement culture-specific knowledge in more meaningful ways in the interim, while culture-generic competence development is fostered alongside it.

What this means for intercultural training and competence development is that current practices need to be re-assessed and re-shaped in order to maximize the effectiveness in training outcomes. While long-term training committment may not seem like an ideal solution to organizations, the business sector needs to rethink its perspective in this regard, because researchers and practitioners alike correlate intercultural competence with team effectiveness [54], capital gain [55], international success [56], financial success
[57]. International business failures, in reverse, have been linked to a lack of intercultural competence (Johnson et al., 2006), have been characterized by a high number of early returns $(25-40 \%)$, with a detrimental effect on the bottom line [58], and have been deemed as costly to a company, time-, money-, and human-resource-wise [59]. With a fairly immediate effect on success, effectivesness, finances and outcomes, businesses would be well advised to consider carefully which kind of intercultural competence training to invest in, as the right type of training may well prove the most cost effective type in the long run.

\section{REFERENCES}

[1] Stadler, S. (2011). Intercultural Competence and its Complementary Role in Language Education. In Perez-Llantada, C. and Watson, M. (eds.), Specialized Languages in the Global Village: A Multi-Perspective Approach. Cambridge: Cambridge Scholar Press, 259-284.

[2] Fantini, A. E. (2000). A central concern: Developing intercultural competence. Available at http://www.brandeis.edu/globalbrandeis/documents/centralco ncern.pdf [Last accessed 19 September 2014].

[3] Johnson, J. P., Lenartowicz, T. and Apud, S. (2006). Cross-cultural competence in international business: Toward a definition and a model. Journal of International Business Studies 37, 525-543.

[4] Beach, M. C., Price, E. G., Gary, T. L., Robinson, K. A., Gozu, A., Palacio, A., Smarth, C., Jenckes, M.W., Feuerstein, C., Bass, E. B., Powe, N. R., and Cooper, L. (2005). Cultural competency: A systematic review of health care provider educational interventions. Med Care 43 (4), 356-373.

[5] Deardorff, D. K. (2004). In search of intercultural competence. International Educator 8 (2), 13-15.

[6] Chen, G.-M. \& Starosta, W.J. (2005). Foundations of Intercultural Communication. $2^{\text {nd }}$ edition. Lanham: University Press of America.

[7] Gudykunst, W. B. (2004). Bridging differences. effective intergroup communication. $4^{\text {th }}$ edition. London: Sage.

[8] Hunter, W. (2004). Knowledge, skills, attitudes, and experiences necessary to become globally competent. Unpublished $\mathrm{PhD}$ thesis, available at http://www.globalcompetence.org/research/WDH-dissertatio n-2004.pdf [Last accessed 29 July 2013].

[9] Langer, E. J. (1989). Mindfulness. Cambridge, MA: Perseus Books.

[10] Takegoshi, K. (2010-2011). Intercultural communication and mental training: How to manage anxiety. 富山大学人間発達 科学部紀要, 5 (1), 113-119.

[11] Spencer-Oatey, H. \& Franklin, P. (2009). Intercultural interaction: A multidisciplinary approach to intercultural communication. London: Palgrave.

[12] Ting-Toomey, S. (1999). Communicating across cultures. New York: The Guildford Press. 
[13] Stanley, S. (1998). In search of cultural competence in psychotherapy and counseling. American Psychologist 53 (4), 440-448.

[14] Hunter, B., White, G. P., \& Godbey, G. (2006). What does it mean to be globally competent? Journal of Studies in International Education 10 (3), 267-285.

[15] Stier, J. (2006). Internationalisation, intercultural communication and intercultural competence. Journal of Intercultural Communication 11: 1-12.

[16] Graham, J. L. \& Lam, N. M. (2003). The Chinese Negotiation. Available at

http:/www.globalnegotiationbook.com/John-Graham-researc h/negotiation-v1.pdf [Last accessed 21 February 2013]

[17] Storti, C. (2009). Intercultural competence in human resources. In D. K. Deardorff (Ed.), The Sage handbook of intercultural competence (pp. 272-286). Thousand Oaks, CA: Sage.

[18] Duronto, P. M., Nishida, T. \& Nakayama, S.-I. (2005). Uncertainty, anxiety, and avoidance in communication with strangers. International Journal of Intercultural Relations 29 (5), 549-560.

[19] Ewington, N. \& Trickey, D. (2006). A World of Difference. London: WorldWork.

[20] Kuan, Y. C. \& Häring-Kuan, P. (1995). Reisegast in China. Dormagen: Iwanowski.

[21] ASTM Business Link. (2001). Available at http://www.astm.org/BIZLINK/BusLinkA01/Chan.html. [Last accessed 5 August 2013].

[22] Australian Trade Commission. (n.d.). Available at http://www.austrade.gov.au/Export/Export-Markets/Countrie s/China/Doing-business. [Last accessed 5 August 2013].

[23] Communicaid. (2009). Available at http://www.communicaid.com/access/pdf/library/culture/doin g-business-in/Doing\%20Business\%20in\%20China.pdf. [Last accessed 5 August 2013].

[24] Flyingblue Club China. (n.d.). Available at http://www.flyingblueclubchina.com/inspire/whats-hot/doing -business-in-china-business-etiquettes. [Last accessed 5 August 2013].

[25] Kwintessential (n.d.). Available at http://www.kwintessential.co.uk/etiquette/doing-business-chi na.html. [Last accessed 5 August 2013].

[26] Bennett, M. J. (2004). Becoming interculturally competent. In J.S. Wurzel (Ed.), Toward multiculturalism: A reader in multicultural education (pp. 62-77). Newton, MA: Intercultural Resource Corporation.

[27] Hammer, M. R. (2012). The intercultural development inventory: A new frontier in assessment and development in intercultural competence. In M. Vande Berg, R. M. Paige \& K. H. Lou (Eds.), Student Learning Abroad (pp. 115-136). Sterling, VA: Stylus.

[28] Hofstede, G. (1980). Culture's consequences: International differences in work related values. Beverly Hills, CA: Sage.

[29] Baskerville-Morley, R. F. (2005). A research note: The unfinished business of culture. Accounting, Organizations and Society 30 (4), 389-391.
[30] Arasaratnam, L. A. and Doerfel, M. L. (2005). Intercultural communication competence: Identifying key components from multicultural perspectives. International Journal of Intercultural Relations 29 (2), 137-163.

[31] Turnbull, C. M. (2009). A history of modern Singapore. Singapore: NUS Press.

[32] Altshuler, L., Sussman, N. M., Kachur, E. (2003). Assessing changes in intercultural sensitivity among physician trainees using the intercultural development inventory. International Journal of Intercultural Relations 27 (4), 387-401.

[33] Stadler, S. (2002). Learning to Disagree in German: The Case of New Zealand University Students. Unpublished MA Thesis, Victoria University of Wellington.

[34] [34] Spitzberg, B. H. (2000). A model in intercultural communication competence. In Larry A. Samovar, R. E. Porter, \& E. R. McDaniel (Eds.), Intercultural communication: A reader (pp. 379-391). Boston, MA: Wadsworth.

[35] Alptekin, C. (2002). Towards intercultural communicative competence in ELT. ETL Journal 56 (1), 57-64.

[36] Smith, P. B. (2002). Culture's consequences: Something old and something new. Human Relations 55 (1), 119-135.

[37] Kirkman, B.L., Lowe, K. B., \& Gibson, C. B. (2006). A quarter century of Culture's Consequences: A review of empirical research incorporating Hofstede's cultural values framework. Journal of International Business Studies 37, 285-320.

[38] McSweeney, B. (2002). Hofstede's model of national cultural differences and their consequences: A triuph of faith - a failure of analysis. Human Relations 55 (1), 89-118.

[39] Crozet, C. \& Liddicoat, A. J. (1999). The challenge of intercultural language teaching: Engaging with culture in the classroom. In J. Lo Bianco, A. J. Liddicoat and C. Crozet (Eds.), Striving for the third place: Intercultural competence through language education (pp.119-129). Melbourne: Language Australia.

[40] Francis, J. N. P. (1991). When in Rome? The effects of cultural adaptation on intercultural business negotiations. Journal of International Business Studies 22 (3), 403-349.

[41] Reid, S. and Stadler, S. (2010) Internationalisation in the UK Higher Education Sector: A Competency-Based Approach. Warwick Occasional Papers in Applied Linguistics \#7. Available from www.globalpeople.org.uk

[42] Jacobson, W., Sleicher, D., and Burke, M. (1999). Portfolio assessment of intercultural competence. International Journal of Intercultural Relations 23 (3), 467-492.

[43] Yamazaki, Y., and Kayes, D. C. (2004). An experiential approach to cross-cultural learning: A review and integration of competencies for successful expatriate adaptation. Academy of Management Learning and Education 3 (4), 362-379.

[44] Spitzberg, B. H. (1989). Issues in the development of a theory of interpersonal competence in the intercultural context. International Journal of Intercultural Relations 13 (3), 241-268

[45] Molinsky, A. L., Krabbenhoft, M. A., Ambady, N. and Choi, Y. S. (2005) Cracking the nonverbal code. Journal of Cross-Cultural Psychology 36 (3), 380-395. 
[46] Gladwell, M. (2008). Outliers. London: Penguin.

[47] St. John, R. (2005). Eight secrets of success. TEDX talk [Available at http://www.ted.com/talks/richard_st_john_s_8_secrets_of_su ccess.html. [Last accessed 7 June 2017]

[48] St. John, R. (2009). Success is a continuous journey. TEDX talk [Available at

$\mathrm{http}: / /$ www.ted.com/talks/richard_st_john_success_is_a_conti nuous journey.html. [Last accessed 7 June 2017]

[49] Beach, M.C., Price, E.G., Gary, T.L, Robinson, K.A., gozu, A., Palacio, A., Smarth, C., Jenckes, M.W., Feuerstein, C., Bass, E.B., Powe, N.R. and Cooper, L.A. (2005). Cultural competency: A systematic review of health care provider educational interventions. Med Care 43(4), 356-373.

[50] Furnham, A. \& Bochner, S. (1982). Social difficulty in foreign culture: An empirical analysis of culture shock. In S. Bochner (ed.), Cultures in contact: Studies in cross-cultural interactions (pp. 161-198). Oxford: Oxford University Press.

[51] Tarique, I. \& Caligiuri, P. (2009). The role of cross-cultural absorptive capacity in the effectiveness of in-country cross-cultural training. International Journal of Training and Development 13(3), 148-164.
[52] Tucker, M.F., Bonial, R. \& Lahti, K. (2004). The definition, measurement and prediction of intercultural adjustment and job performance among corporate expatriates. International Journal of Intercultural Relations 28, 221-251.

[53] Nonaka, I. and Takeuchi, H. (1995). The Knowledge-Creating Company: How Japanese Companies Create the Dynamics of Innovation. Oxford: Oxford University Press.

[54] Callen, D. (2008). Leveraging global virtual teams through intercultural curiosity, sensitivity, and respect. Graziadio Business Review 11.

[55] Horchani, T. And Hosni, M. (2012). Impact of intercultural training on the development of intercultural competences. European Journal of Business and Social Sciences 1 (2), $35-47$.

[56] Le Boterf, G. (1994). De la compétence. Essai sur un attracteur étrange. Paris: Les Éditions d'organisation.

[57] Mayrhofer, U. (2005). Les rapprochements, forme d'internationalisation privilégiée par les entreprises? Revue internationale de gestion, hiver.

[58] McEvoy, G.M. (2011). Reducing the Cost of Expatriation in Austere Times: A Case Study of Two Organizations. Journal of International Management Studies 6 (1), 1-9.

[59] Tung, R.L. (1993). Managing cross-national and intra-national diversity. Human Resource Management 32 (4), 461-477. 